\section{$\underset{\substack{\text { hommes } \\ \text { \& migrations }}}{ }$}

\section{Hommes \& migrations}

Revue française de référence sur les dynamiques

migratoires

$1305 \mid 2014$

L'exil chilien en France

\title{
L'accueil des réfugiés politiques chiliens à Grenoble.
}

\section{Anouchka Hrdy}

\section{(apenEdition \\ Journals}

\section{Édition électronique}

URL : http://journals.openedition.org/hommesmigrations/2723

DOI : 10.4000/hommesmigrations.2723

ISSN : 2262-3353

\section{Éditeur}

Musée national de l'histoire de l'immigration

Édition imprimée

Date de publication : 1 janvier 2014

Pagination : 89-94

ISBN : 978-2919-040261

ISSN : $1142-852 X$

\section{Référence électronique}

Anouchka Hrdy, "L'accueil des réfugiés politiques chiliens à Grenoble. », Hommes \& migrations [En ligne], 1305 | 2014, mis en ligne le 01 janvier 2017, consulté le 02 mai 2019. URL : http:// journals.openedition.org/hommesmigrations/2723; DOI : 10.4000/hommesmigrations.2723 


\title{
L'ACCUEIL DES RÉFUGIÉS POLITIQUES CHILIENS À GRENOBLE
}

par ANOUCHKA HRDY, diplômée du master Histoire économie et société des mondes contemporains, université Pierre Mendès-France-Grenoble-II.

\author{
La question de l'exil, et plus précisément de la venue des \\ réfugiés politiques chiliens en France, permet de questionner \\ les conditions de l'accueil réservé aux demandeurs d'asile \\ actuels. L'histoire des réfugiés chiliens à Grenoble prend \\ aujourd'hui une dimension mythique à tel point qu'on peut \\ se demander comment leur accueil a été possible dans la \\ bienveillance générale, dans une ville où l'on mure aujourd'hui \\ les bâtiments vides pour les rendre indisponibles aux \\ demandeurs d'asile.
}

S'intéresser à l'histoire de l'exil depuis le pays d'accueil, c'est aussi s'intéresser aux solidarités, aux pratiques militantes, aux rapports aux pouvoirs publics et au positionnement des institutions visà-vis des exilés. Prendre l'exil comme objet d'histoire revient à étudier la mise en pratique des politiques d'immigration. Le milieu des années 1970 marque en cela une étape cruciale, et étudier l'accueil des Chiliens en France, c'est s'intéresser à une période clé de la structuration, de l'institutionnalisation et de la mise à l'épreuve des politiques d'accueil actuelles. J'ai dans mon travail envisagé cette problématique à une micro-échelle en prenant comme terrain de recherche l'agglomération grenobloise. Ce choix fut motivé par plusieurs facteurs : le premier vient de la réputation actuelle de la ville de Grenoble par rapport à ses capacités d'accueil de jadis, le second est la "reconnaissance" des réfugiés eux-mêmes vis-à-vis de cette ville qui les accueillis. Si j'ai tout d'abord tenté de caractériser le phénomène de l'asile chilien dans cette agglomération, il m'est bien vite apparu que l'intérêt véritable du sujet réside dans la compréhension des mécanismes qui ont permis cet asile et dans les processus qui en ont rendu les pratiques atypiques et novatrices à l'échelle nationale. En effet, ce n'est pas tant par le nombre des Chiliens accueillis que Grenoble se distingue ${ }^{1}$, mais par la forme et la qualité 
de son accueil. Nous nous appuierons sur des recherches en archives et sur 47 entretiens de militants associatifs et d'exilés chiliens, dont 6 retournés vivre au Chili. La collecte de cette mémoire m'a incité à m'intéresser plus particulièrement à deux centres ${ }^{2}$ : le foyer de la rue Émile-Gueymard et le centre d'hébergement éclaté de La Villeneuve.

\section{Logique caritative et accueil paternaliste}

Le premier centre d'accueil s'organise autour d'une logique paternaliste et caritative caractéristique de cette période de l'exil, que l'on croit court et accidentel. Ouvert dans l'urgence, il se situe dans le centre-ville, en face de la gare, et émane de la volonté et de l'énergie de sympathisants de l'Unité populaire et de militants de gauche, dont certains reviennent justement d'un séjour politique au Chili à l'automne 1973, ainsi que de bénévoles d'associations de défense des droits de l'homme. Ouvert de janvier à septembre 1974, le foyer naît de l'action de volontés politiques citoyennes, de la gestion des religieuses du Secours catholique, appuyées par des bénévoles de la Cimade

Le premier foyer d'accueil ouvert pour les Chiliens à Grenoble est le fruit de l'urgence. Par ailleurs, les militants étaient

disposés à se mobiliser, même si paternalisme chrétien et approche caritative étaient prédominants. et une foule de curieux et de militants venus apporter soutien matériel et psychologique aux réfugiés accueillis, et avec le soutien financier de la municipalité. Un consensus unit ces trois acteurs autour de l'accueil des victimes du coup d'État au Chili, par-delà les divergences idéologiques. Tout le monde s'accorde sur la nécessité de leur venir en aide, au nom de la démocratie: "Tu sais, il n'y a pas de comparaison avec les réfugiés politiques espagnols, qui étaient parqués à Tou-
Exiliados, le refuge chilien en Isère 1973-2013,

Musée de la résistance et de la déportation, Maison des droits de I'homme, Isère (c) D.R.

louse, dans le Var... Allende a créé une image incroyable. La solidarité avec le peuple chilien était le fait de la gauche surtout, mais aussi de la droite démocratique. Nous avons eu le soutien de tout le monde 3 ."

Au cœur de l'hiver, un appel à la solidarité est lancé dans la région grenobloise, et entendu. Des bénévoles se pressent au foyer afin de prêter main-forte, apportant leur aide, des vêtements chauds, un soutien amical. On guide les Chiliens à travers les méandres de l'administration française et on essaie de réunir toutes les conditions possibles pour une intégration rapide : cours de langue, accompagnement aux entretiens d'embauche et aux visites médicales, assistance lors de l'emménagement dans de nouveaux logements... les exilés sont accompagnés dans tous les aspects de la vie quotidienne. Mais des règles strictes régissent leur quotidien, 
comme les heures d'entrée et de sortie du foyer, contre lesquelles les réfugiés se mobiliseront plusieurs fois, comme en témoigne cette exilée : "Il y avait beaucoup de dames du Secours catholique. C'étaient des personnes âgées... On ne nous laissait pas sortir. À neuf heures du soir il fallait que l'on soit dans la chambre. C'était très militaire au début. Ils disaient que c'était pour notre sécurité. Qu'ils avaient peur pour nous. Et qu'il fallait mettre des règles parce qu'il fallait que l'on s'adapte aux règles. On a protesté, on s'est réunis, on a dit qu'on était des adultes ${ }^{4} . .$.

Un élément est ici intéressant à noter, la volonté et la capacité des Chiliens à prendre en main leur quotidien. Nous noterons l'étonnante liberté laissée aux réfugiés pour se réunir, s'organiser et revendiquer auprès de la structure qui les accueille la modification de certains fonctionnements : "Comme nous étions les 'pauvres Chiliens', je me souviens qu'on nous apportait des vêtements, des chaussures, par sacs énormes! Les gens nous donnaient avec tant de bonne volonté! Les Chiliennes et les Chiliens prenaient les sacs, sortaient ce qui les intéressait. Dans une réunion, ils mont nommé trésorier et responsable de tous ces vêtements, afin que je les répartisse en fonction des besoins. Il y avait un espace dans le grenier. J'ai pris les vêtements, je les ai triés par taille... J'ai fait mon magasin! Je devais aussi répartir l'argent qu'on nous donnait entre chaque famille. J'avais un pouvoir de décision sur l'organisation. En tant que trésorier, je devais mettre de l'ordre. À l'époque, comme on venait du Chili, la nourriture française n'était pas si agréable pour nous. Avec l'argent qu'on leur donnait, les gens ont commencé à acheter des petites cuisinières à gaz, une casserole, une poêle... et à faire à manger dans leur chambre! Le problème, c'est qu'il pouvait y avoir un accident, un incendie. Il a donc fallu interdire ces pratiques. On leur a proposé de nous donner l'argent pour que nous leur fassions à manger. Et ils ont accepté. Ils ont fait une cuisine collective. Ils ont amené les cuisinières, les frigos, et les gens ont commencé à venir, à préparer les biberons pour les enfants... Toutes les semaines, on faisait des réunions avec le comité d'agglomération. Nous, on exposait nos problèmes, et eux, ils les prenaient en comptes."
Le premier foyer d'accueil ouvert pour les Chiliens à Grenoble est le fruit de l'urgence. Par ailleurs, les militants étaient disposés à se mobiliser, même si paternalisme chrétien et approche caritative étaient prédominants. Précisons que c'était la première fois que la France accueillait des réfugiés non européens.

\section{Un système d'accueil pragmatique et novateur}

Le foyer de la rue Émile-Gueymard ferme ses portes en septembre 1974, mais les exilés continuent d'arriver à Grenoble. Accueillis chez des proches et des connaissances, ces Chiliens viennent gonfler petit à petit la communauté naissante.

Lorsque, en 1976, le gouvernement de Pinochet applique la commutation des peines de prison en peine d'exil, les réfugiés chiliens grenoblois s'unissent aux associations de soutien aux réfugiés argentins afin de solliciter la ville de Grenoble. Ils mettent alors en place un système d'accueil pragmatique et novateur :

le centre d'hébergement L'idée principale de cette éclaté de La Villeneuve gestion n'est plus seulement est en effet unique en son d'accompagner les exilés genre.

Forts de leur propre expé- les moyens d'accéder à rience, les réfugiés chiliens l'autonomie. déjà installés parviennent

à négocier la gestion tripartite d'un centre porté notamment par l'Association grenobloise de solidarité franco-argentine (AGSFA), pensé sous la forme d'appartements autonomes gérés conjointement par la Direction départementale des affaires sanitaires et sociales (DDASS) et le Service civil international (SCI). Nous sommes donc en présence de trois acteurs principaux, appartenant tous à la société civile, avec la participation citoyenne et militante émanant de Chiliens déjà accueillis. C'est dans cette participation que réside toute la nouveauté de ce centre : siègent au conseil 
d'administration des personnes ayant vécu très récemment la situation qu'ils tentent de gérer. La mise en place d'un centre d'accueil devient à la fois un combat militant en soi et une manière inédite de gérer ce type de structure. Ce ne sont donc plus des associations caritatives qui prennent en main l'accueil, mais une assemblée collégiale regroupant à la fois des personnes ayant fait l'expérience de l'exil - les Chiliens -, des personnes ayant un réseau associatif à mobiliser - les Français et les Argentins de l'AGSFA -, et l'assise institutionnelle qu'apporte le SCI.

Concrètement, le centre fonctionne de la façon suivante: "Neuf appartements éclatés dans La Villeneuve étaient mis à notre disposition. Les personnes nous étaient envoyées par France-Terre d'asile. Donc on les accueillait, on allait les chercher à la gare, on les installait et après on faisait tout l'accompagnement social, avec le centre de santé,

La mainmise de l'État sur les organisations de réfugiés

et l'institutionnalisation de la question prennent place dans un contexte de "mondialisation du droit d'asile" formalisé par la ratification de la convention de Genève par plus de 160 États. les écoles... On mettait les familles dans un appartement et ils touchaient une somme journalière de la DDASS, suivant le nombre de personnes, le nombre d'enfants, etc. Normalement, ils ne devaient rester que six mois en centre d'hébergement. C'était un passage. Donc, on avait toute la partie demande de logement, recherche d'emploi, à gérer. Moi, j'allais voir, entre autres, les élus au logement. On faisait des dossiers et on s'occupait de leur suivi. Il y avait des commissions d'attribution, et nous faisions en sorte que les gens soient prioritaires ${ }^{6}$."

Pendant cette période de six mois, les réfugiés reçoivent l'aide d'assistantes sociales et de travailleurs sociaux pour trouver un travail, une formation, un logement, des cours de langue, ou encore pour comprendre les démarches administratives nécessaires à leur installation. Les professionnels de l'insertion ont remplacé les bénévoles et la structure tend à s'institutionnaliser. L'idée principale de cette gestion n'est plus seulement d'accompagner les exilés mais aussi de leur fournir les moyens d'accéder à l'autonomie. Plus de gestion collective du quotidien, l'originalité réside dans la liberté et l'autonomie accordées aux réfugiés et aux demandeurs d'asile. Un réfugié qui a connu deux expériences d'accueil différentes témoigne de l'originalité du centre de La Villeneuve : "À La Villeneuve, ils donnaient un appartement meublé avec l'aide des associations de solidarité et un peu d'argent, dont les personnes pouvaient faire ce qu'elles voulaient. Elles pouvaient commencer un peu à panser les plaies et à se reconstruire, de façon familiale. C'était nouveau, ici, en Isère, essentiellement à Grenoble. J'ai connu deux expériences. Quand je suis arrivé, jai été accueilli en HauteSavoie, à Saint-Pierre-de-Faucigny, un petit village perdu entre Annecy et Bonneville. Nous étions arrivés dans un foyer Sonacotra qui n'était pas du tout adapté à l'accueil d'exilés politiques. L'argent était géré par d'autres associations. Et de ce côté-là je me suis bagarré. J'ai créé une association et j'ai failli me faire expulser de France. Parce qu'on demandait des comptes, on demandait quills respectent nos droits. Nous étions des militants, pour la plupart nous sortions de prison. Nous, on connaissait notre droit international ${ }^{7} . . . "$

Globalement, l'accueil dans ce centre d'hébergement éclaté semble avoir été très positivement vécu par les réfugiés. Un témoin nous raconte son arrivée à l'Arlequin, un vendredi à 18 heures : "Bonjour, je vous attendais! Vous êtes maintenant sous notre protection. Vous allez monter, prendre l'ascenseur et aller à l'appartement 312, au $3^{e}$ étage.' Nous sommes montés, il nous a donné les clefs. Ce nétait pas comme à Paris, à je ne sais combien dans une chambre minuscule, dans des conditions insalubres des fois... Tout le monde était ravi. Nous avions un appartement grand comme un terrain de foot! Les filles avaient une chambre chacune. L'appartement était meublé, le frigo plein. L'homme qui nous avait reçus m'avait dit: 'On se verra lundi à 8 heures, je viendrai vous chercher.' Et il m'avait donné une enveloppe. Dedans, il y avait 500 francs : 'Ça, cest pour le week-end.' Mes filles étaient à la crèche et à l'école le lundi matin! C'est le foyer qui les avait inscrites. Ils avaient tout pris en charge. C'était extraordi- 
naire! Moi, trois mois après, j'avais du boulot! Le stage de langue, cétait huit heures par jour 8 !"

Aujourd'hui encore, la mémoire collective retient que la communauté chilienne, c'est La Villeneuve. L'éclatement du centre sur le quartier, la longévité de son activité - plus de huit ans d'existence -, l'implication auprès des réfugiés des diverses structures sociales, culturelles et politiques ont fait de La Villeneuve un port d'attache pour ces Chiliens. Le centre a ainsi eu une action re-territorialisante ${ }^{9}$ sur ces "déracinés" que sont les exilés, et le quartier est devenu l'épicentre de la communauté, agissant comme un élément identitaire fort. "Je fais partie des murs de La Villeneuve", déclare un témoin lors d'un entretien ${ }^{10}$. Être chilien de La Villeneuve, c'est avoir participé à "lâge d'or" du quartier et avoir vécu une époque communautaire forte.

\section{L'institutionnalisation de l'accueil des demandeurs d'asile}

Un survol historique est nécessaire pour comprendre les relations entre les institutions et l'accueil : les offices de réfugiés qui ont assuré pendant près d'un siècle le secours des étrangers entre la Monarchie de Juillet et la Seconde Guerre mondiale sont les cellules embryonnaires des associations contemporaines de défense du droit d'asile et d'accueil des réfugiés politiques. Le décret-loi du 2 mai 1938 soumet à autorisation les associations étrangères. Bien que prenant place dans le contexte de repli national d'avant-guerre, ce décret marque la première phase de la stratégie visant à instaurer un contrôle étatique et national total sur la politique d'accueil des réfugiés. "La manière dont l'administration française a réussi à marginaliser progressivement toutes les formes autonomes d'expression collective que sétaient données les réfugiés est significative de l'extension du pouvoir bureaucratique ${ }^{11}$." Si l'État s'attaque aux associations et comités créés par des étrangers et pour des étrangers, la création de l'Office français de protection des réfugiés et apatrides (Ofpra) signe l'arrêt de mort des offices de bienfaisance. Le 31 janvier 1952, en effet, tous sont supprimés par acte d'autorité. La naissance de l'Ofpra entraîne la création d'un organisme administratif entièrement nouveau. La mainmise de l'État sur les organisations de réfugiés et l'institutionnalisation de la question prennent place dans un contexte de "mondialisation du droit d'asile ${ }^{12 "}$ formalisé par la ratification de la convention de Genève par plus de 160 États. La
L'accueil dans toutes ses composantes participe à la construction identitaire du réfugié dans l'exil. Notons que le niveau d'insertion-sociale et professionnelle - des réfugiés diffère en fonction des centres dans lesquels ils ont été accueillis. "toute-puissance des instances nationales ${ }^{13 \text { " }}$ 'exprime dans la dissolution des organismes communautaires, au profit d'une institution relayée sur le terrain par des associations régies par la loi de 1901, à l'instar du Secours catholique ou de la Cimade.

Ces associations, à caractère principalement humanitaire et caritatif, se voient rejointes dans les années 1970 par France-Terre d'asile (FTDA), association de solidarité laïque qui prend dès 1975 la tête du Dispositif national d'accueil (DNA). Le fondement de son action est la protection des droits de l'homme et l'égalité de tous en droit, et non l'aide accordée par éthique à toute personne dans le besoin. Concrètement, la conséquence de ce glissement de posture est l'impact que l'association aura à la fois sur l'opinion publique et sur le monde politique. FTDA plaide pour la mise en place d'un service public d'État d'aide aux réfugiés, entièrement financé par les pouvoirs publics, et défend une conception de laction publique selon laquelle les pouvoirs publics sont responsables de l'instauration de droits ${ }^{14}$. En 1975, la création de Coordination réfugiés, forte de cinq des associations délégataires du DNA et reconnues par les pouvoir publics, entérine l'idée que les associations jouent le rôle de 
délégation de service public. La coordination et les pouvoirs publics se réunissent alors au sein d'un comité de liaison chargé de faire connaître l'actualité des réalités de terrain. L'information est ensuite relayée par les comités locaux, qui intègrent sur place d'autres acteurs associatifs non gestionnaires du DNA. Par cette reconnaissance institutionnelle, l'État fait des associations le principal acteur de la politique publique en matière de droit d'asile.

\section{Un combat pour la dignité des réfugiés}

L'accueil dans toutes ses composantes participe à la construction identitaire du réfugié dans l'exil. Notons que le niveau d'insertion - sociale et professionnelle - des réfugiés diffère en fonction des centres dans lesquels ils ont été accueillis. Si les réfugiés du premier foyer témoignent d'une insertion professionnelle d'un niveau supérieur ou égal à celle qu'ils avaient en quittant le Chili, les réfugiés du centre d'accueil ne vivent pas la même ascension sociale dans l'exil. Les réfugiés accueillis dans les centres de travailleurs immigrés, dont nous n'avons pas parlé ici, subissent au contraire un certain déclassement professionnel. La question du retour dépend également de l'accueil : il m'est apparu que seuls les réfugiés n'ayant pas bénéficié d'un accueil en foyer ou dans un centre dédié aux réfugiés chiliens ont entrepris un voyage de retour définitif. La poursuite de ces recherches devrait permettre d'affiner ces observations et de comprendre comment l'accueil d'une population influence sa constitution communautaire, les liens qui se tissent entre elle et la société d'accueil, et ce qui transforme un mouvement migratoire en diaspora.

Étudier la question de l'accueil d'un point de vue historique permet d'appréhender les différentes composantes qui l'ont rendu effectif et d'identifier les acteurs qui y ont réellement participé. Il ne s'agit pas, comme on le pense souvent aujourd'hui des partis politiques, mais des citoyens et des bénévoles, puis des réfugiés eux-mêmes. Cet accueil occupe une place au cœur du parcours des exilés, mais aussi et surtout informe sur la société qui reçoit. Ainsi, on observe à Grenoble, en ce début des années 1970, un glissement dans la façon d'accueillir. Les pratiques traditionnellement issues d'une culture religieuse et caritative s'érodent au contact de populations nouvelles, non européennes, pour se souder autour de nouvelles valeurs politiques de solidarité entre les peuples. Le droit d'asile rappelle, au tournant de l'année 1976, la situation de 1973, pour se concrétiser sous la forme d'un centre d'hébergement éclaté : ce n'est plus le principe de charité qui anime les militants de l'accueil, mais bien la reconnaissance de l'égalité en droit des êtres humains. 